\title{
TEOR DE PIGMENTOS CLOROPLASTÍDICOS, CRESCIMENTO E PRODUTIVIDADE EM PLANTAS DE ARROZ (Oryza sativa, L), SUBMETIDAS À DOSES CRESCENTES DE NITROGÊNIO
}

\section{CONTENT OF CHLOROPLASIDIC PIGMENTS, GROWTH AND PRODUCTIVITY IN RICE PLANTS (Oryza sativa, L), SUBMITTED TO GROWTH DOSES OF NITROGEN}

\author{
Susana Silva Conceição ${ }^{1}$; Edson Ugulino Lima ${ }^{2}$; Leonardo Brandão Araújo ${ }^{3}$ Cândido Ferreira \\ de Oliveira Neto ${ }^{4}$; Jessivaldo Rodrigues Galvão ${ }^{5}$
}

DOI: https://doi.org/10.31692/978-65-991061-7-0.42-52

\section{RESUMO}

O objetivo deste trabalho foi avaliar o crescimento, produção de massa seca e teor de pigmentos fotossintéticos em plantas de arroz (Oryza sativa, L), cultivar BRS Jaçanã em função de diferentes doses de nitrogênio. O experimento foi conduzido em Latossolo Amarelo, textura média, encontrados na Universidade Federal Rural da Amazônia - UFRA, Campus Belém-PA. Foram avaliadas quatro doses de nitrogênio $(60,120,180,240 \mathrm{~kg} / \mathrm{ha})$ na forma de Uréia à $45 \%$, e uma testemunha $\left(0 \mathrm{~kg} \mathrm{~N} / \mathrm{ha}^{-1}\right)$. O delineamento experimental foi totalmente casualisado, com cinco repetições perfazendo 25 unidades experimentais. Foram usados $6 \mathrm{~kg}$ do solo/vaso nas doses correspondentes aos tratamentos. A cultura do arroz foi beneficiada pela adubação nitrogenada. Os maiores incrementos na altura, produtividade e no teor de pigmentos cloroplastídicos ocorreram com a dosagem de $120 \mathrm{~kg} \mathrm{~N} / \mathrm{ha}^{-1} \mathrm{e} 180 \mathrm{~kg} \mathrm{~N} / \mathrm{ha}^{-1}$. Sob efeito destes tratamentos, as plantas atingiram, respectivamente, crescimento de 48 e $65 \mathrm{~cm}$ e massa seca de 25 e 20g/vaso, em que para esta última variável, houve decréscimo na medida em que a concentração de nitrogênio no meio de cultivo foi superior a $120 \mathrm{~kg} \mathrm{~N} / \mathrm{ha}^{-1}$. A dosagem de 240 $\mathrm{kg} / \mathrm{ha}^{-1}$ provocou uma redução significativa no teor de pigmentos cloroplastídicos, Sob essa suplementação nitrogenada, as plantas apresentaram teores de clorofila $a, b$ total e carotenóide de 20,6, 26 e $10 \mathrm{mg} \mathrm{g}^{-1}$, respectivamente. Os maiores decréscimos ocorreram para a concentração de clorofila $b$, havendo redução de $60 \%$ na concentração do pigmento quando comparado às plantas tratadas com nitrogênio $180 \mathrm{~kg} \mathrm{~N} / \mathrm{ha}^{-1}$, indicando que a maior suplementação nitrogenada, interferiu em processos bioquímicos relacionados à síntese de proteínas e na composição da molécula de clorofila com reflexos negativos sobre processos fotossintéticos, o que provavelmente, deve-se ao acúmulo de nitrogênio na forma de nitrato, e sua não utilização nas vias metabólicas das plantas o que ocasionou menor crescimento e produtividade da cultura.

Palavras-Chave: Adubação nitrogenada, arroz, produtividade, clorofila.

\begin{abstract}
The objective of this work was to evaluate the growth, dry mass production and photosynthetic pigment content in rice plants (Oryza sativa, L), cultivar BRS Jaçanã as a function of different nitrogen doses. The experiment was conducted in Yellow Latosol, medium texture, found at the Federal Rural University of Amazonia - UFRA, Campus Belém-PA. Four nitrogen doses (60, $\left.120,180,240 \mathrm{~kg} / \mathrm{ha}^{-1}\right)$ in the form of Urea at $45 \%$, and one control $\left(0 \mathrm{~kg} \mathrm{~N} / \mathrm{ha}^{-1}\right)$ were evaluated.

\footnotetext{
${ }^{1}$ Engenharia Agronômica, Universidade Federal Rural da Amazônia-UFRA, su tseliot@yahoo.com.br

${ }^{2}$ Administração, Universidade da Amazônia-UNAMA, edsonugu@ yahoo.com.br

${ }^{3}$ Engenharia Agronômica, Universidade Federal Rural da Amazônia-UFRA, leonardo029@ gmail.com

${ }^{4}$ Engenharia Agronômica, Universidade Federal Rural da Amazônia-UFRA, candido.neto@ufra.edu.br

${ }^{5}$ Prof, Dr. Em Agronomia, Universidade Federal Rural da Amazônia-UFRA, jessivaldo.galvao@ufra.edu.br
} 
The experimental design was totally randomized, with five replicates 25 experimental units. 6 $\mathrm{kg}$ of the soil / pot were used in the doses corresponding to the treatments. Rice cultivation was benefited by nitrogen fertilization. The highest increases in height, productivity and chloroplastidic pigment content occurred at a dosage of $120 \mathrm{~kg} \mathrm{~N} / \mathrm{ha}^{-1}$ and $180 \mathrm{~kg} \mathrm{~N} / \mathrm{ha}^{-1}$. Under these treatments, the plants reached growth of 48 and $65 \mathrm{~cm}$ and a dry mass of 25 and $20 \mathrm{~g} /$ pot, respectively, in which, for the latter, there was a decrease in the concentration of nitrogen in the culture medium at $120 \mathrm{~kg} \mathrm{~N} / \mathrm{ha}^{-1}$. A total of $20 \mathrm{~kg} / \mathrm{ha}^{-1}$ of chlorophyll $\mathrm{a}, \mathrm{b}$ and carotenoid chlorophyll $\mathrm{a}, \mathrm{b}$, and $10 \mathrm{mg} \mathrm{g}-1$, respectively. The highest decreases occurred for the concentration of chlorophyll $\mathrm{b}$, with a reduction of $60 \%$ in the pigment concentration when

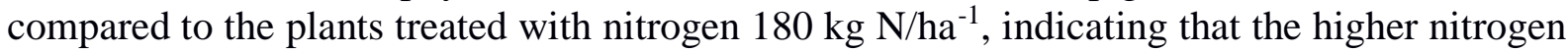
supplementation interfered in biochemical processes related to the synthesis of proteins and in the composition of the chlorophyll molecule with negative reflections on photosynthetic processes, probably due to the nitrogen accumulation in the nitrate form, and its non-use in the metabolic pathways of the plants, which caused less growth and productivity of the crop.

Keywords: Nitrogen fertilization, rice, productivity, chlorophyll.

\section{INTRODUÇÃO}

$\mathrm{O}$ arroz (Oryza sativa,L) está entre as culturas mais valorizadas no mercado global. Segundo dados da FAO, a produção mundial do ceral em 2017, foi de 481,5 milhões de toneladas e, nesse cenário, o Brasil destaca-se ocupando a nona posição entre os maiores produtores mundiais da cultura, encontrando no sul do país os principais centros de produção (MAKINO 2011; FAO, 2016).

Nos cereais a adubação nitrogenada é baseada na recomendação da Comissão de Química e Fertilidade do Solo para o Rio Grande do Sul e Santa Catarina (COMISSÃO, 2004). No entanto, ainda ocorrem imprecisões, havendo em muitos casos uma sub ou supresestimativa na utilização do nutriente o que implica em perdas produtivas e gastos desnecessários com fertilizante nitrogenado (ARGENTA et al., 2003). Segundo ARF et al. (2003), a resposta à adubação nitrogenada é variável: pode apresentar incremento de produtividade com doses superiores a $100 \mathrm{~kg} /$ ha de $\mathrm{N}$, ou não mostrar resultados significativos para esses parâmetros.

$\mathrm{O} \mathrm{N}$ é o nutriente mais absorbido e, por tanto, o que mais limita o crescimento e o desenvolvimento vegetal (NASCENTE et al., 2011; COSTA et al., 2016). Quando absorvido em excesso, acumula-se como $\mathrm{NO}_{3}{ }^{-}$e, sob essa forma, não é utilizado em vias metabólicas das plantas para a síntese de compostos orgânicos como enzimas e proteínas envolvidas na regulação de processos de crescimento e de desenvolvimento vegetal.

No arroz, por exemplo, altas concentrações de $\mathrm{N}$ podem provocar redução na frutificação mas, por outro lado, sua deficiência causa decréscimos no tamanho de folhas devido à diminuição do número de células e redução do crescimento com possível aumento no comprimento das raízes (He WM et al. 2011). Além disso, um sintoma característico da deficiência de Né o surgimento de clorose, inicialmente, nas folhas mais velhas como resultado 
da preteólise ou inibição da síntese da molécula de clorofila, tendo em vista ser um constituinte estrutural do pigmento fotossintético (GOMES; \& MAGALHÃES, 2004).

O teor de clorofila na folha é utilizado para predizer o nível nutricional de nitrogênio em plantas, devido ao fato da quantidade desse pigmento correlacionar-se positivamente as taxas de fotossíntese e com teor de $\mathrm{N}$ no vegetal, sendo um fator importante para determinar o potencial de produção de biomassa em diversas espécies vegetais (PIEKIELEK \& FOX, 1992; BOOIJ et al., 2000; MAKINO, 2011).

O funcionamento da maquinaria bioquímica das plantas apresenta intrínseca relação com o estado nutricional das mesmas, o que aparece como fator determinante para a melhoria dos parâmetros agronômicos. Restritas pesquisas apontam a relação entre a concentração de pigmentos cloroplastídicos em função da adubação nitrogenada.

Neste aspecto, o presente trabalho teve como objetivo estudar os efeitos de doses crescentes de nitrogênio sobre a produtividade e teor de clorofila $a, b$, clorofila total e carotenóides na cultivar de arroz BRS Jaçanã e correlacioná-los aos parâmetros de crescimento e produção de biomassa.

\section{METODOLOGIA}

O experimento foi conduzido no período de junho a outubro de 2010, em casa de vegetação pertencente a Universidade Federal Rural da Anazônia-UFRA situada à $01^{\circ} 28^{\prime} 03$ ”'S; 48 29'18' W. Do campus, foram coletadas amostras de solo de uma camada arável $(0-20 \mathrm{~cm})$ de profundidade, de um Latossolo Amarelo, textura média.O material foi colocado em vaso, cada um contendo $6 \mathrm{~kg}$ de Terra Fina Secas ao Ar (TFSA). Pelo método gravimétrico, foi obtido o volume de água no interior de cada recipiente, conforme descrito por Klar et al., (1966), com modificações. Os vasos foram umedecidos até aproximadamente $70 \%$ da umidade de saturação e anotados o peso do conjunto, solo úmido e do vaso. A água perdida por evaporação e transpiração foi reposta diariamente, baseada no peso inicial. Nesta pesquisa, foi utilizada a cultivar de arroz BRS jaçanã e, para tanto, foram plantadas quinze sementes por vaso e, neste momento, adicionadas doses crescentes de nitrogênio. Aos cinco dias após a germinação efetuou-se o desbaste para 10 plantas. O delineamento experimental foi o inteiramente casualizado (DIC) e consistiu de cinco tratamentos, sendo quatro dosagens de nitrogênio (60, 120, 180, $\left.240 \mathrm{~kg} / \mathrm{há}^{-1}\right)$, na forma de (Uréia 45\%), e um em forma de testemunha $\left(0 \mathrm{~kg} \mathrm{~N} / \mathrm{há}^{-1}\right)$ com cinco repetições, totalizando 25 unidades experimentais.

\section{Determinação das variáveis de crescimento e produtividade}

As plantas foram mantidas sob o tratamento por 120 dias e ao final do período 
experimental, mensurada a altura e determinada a produtividade. Para isso, coletou-se as panículas das plantas de arroz em uma área de $4,0 \mathrm{~m}^{2}$ de cada unidade experimental e as amostras foram trilhadas e os grãos secados ao sol e pesados em balança analítica. Em seguida, as plantas foram secionadas na altura da superfície do solo e determinada a matéria seca (MS). Para tanto, o material vegetal foi armazenado em saco de papel e seco em estufa com ventilação de ar forçado a $60^{\circ} \mathrm{C}$ até a obtenção do peso constante.

\section{Determinação do teor de clorofila $a, b$ total e carotenóide}

Foram coletadas amostras do segundo par de folhas totalmente expandidas e os teores de clorofilas $a, b$ e total e carotenóides determinados conforme ARNON (1949), a partir de $0,25 \mathrm{~g}$ de tecido foliar o qual foi macerado na presença de $5 \mathrm{ml}$ de acetona $80 \%(\mathrm{v} / \mathrm{v}) \mathrm{em}$ banho de gelo. Posteriormente, o extrato foi filtrado a vácuo e o volume completado para $25 \mathrm{ml}$ com acetona $80 \%$. Os extratos obtidos foram submetidos à leitura das absorbâncias por meio de espectrofotômetro nos comprimentos de onda 663, 537 e $652 \mathrm{~nm}$ para as clorofilas $a, b$ e total, respectivamente, e $470 \mathrm{~nm}$ para os carotenóides.

Os dados para cada variável foram submetidos a análises de regressão linear e quadrática, utilizando-se o programa SISVAR (FERREIRA, 2011).

\section{RESULTADOS E DISCUSSÃO}

Todas as características de produtividade, como crescimento, produção de massa seca e de produção de grãos, na cultivar BRS jaçanã, apresentaram variação significativa $(p<0,05)$ em função das concentrações de nitrogênio utilizadas e as médias geradas pelos dados foram ajustadas a modelos quadráticos de regressão.

A maior altura das plantas de arroz $(65 \mathrm{~cm})$ foi obtida com a dosagem de $180 \mathrm{~kg} \mathrm{~N} / \mathrm{ha}^{-}$ 1, (Figura 1). Segundo Freitas et al (2000), em cereais, com a aplicação de doses elevadas de nitrogênio, antes do ponto de crescimento, transformar-se em estrutura reprodutiva ocorre um aumento na produção de fitormônios, especialmente de auxinas, estimulando com isso a divisão e a expansão celular, aumentando portanto, o tamanho do caule e, conseqüentemente, a altura das plantas. No entanto, houve um decréscimo significativo na variável analisada quanto a dosagem de $\mathrm{N}$ atingiu valor máximo de $240 \mathrm{Kg} \mathrm{N} / \mathrm{ha}^{-1}$, mostrando que quando se aumenta muito a adubação nitrogenada em solos cultivados com plantas de arroz, esse aumento pode provocar uma diminuição no crescimento em plantas de arroz.

Figura 1: Altura de plantas de arroz (Oryza sativa L), submetidas a doses crescentes de nitrogênio. Fonte própria 


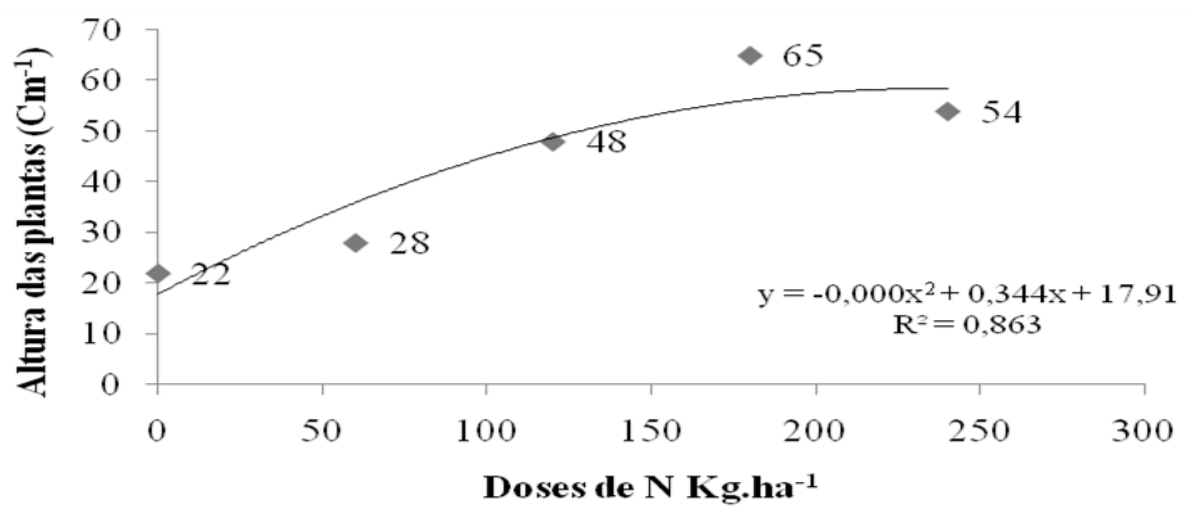

Autores como Heringer \& Moogen (2002), afirmam que à medida que a quantidade de $\mathrm{N}$ aplicado ultrapassa a capacidade da planta em absorvê-lo, o nutriente pode se acumular nos tecidos, reduzindo sua eficiência de aproveitamento e, com isso, diminuindo seu crescimento. Considera-se a partir disso, que algo similar ocorreu nesta pesquisa.

A aplicação de $\mathrm{N}$ provocou diferentes alterações no acúmulo de biomassa da gramínea durante 120 dias após a suplementação com o nutriente (Figura 2). Sob efeito da menor e maior dosagem de nitrogênio $60 \mathrm{~kg} \mathrm{~N} / \mathrm{ha}^{-1}$ e $240 \mathrm{~N} \mathrm{~kg} \mathrm{~N} / \mathrm{ha}^{-1}$,concomitantemente, e sob estes tratamentos, não houve incrementos significativos $(\mathrm{p}>0,05)$ para a MS, sendo encontrados, respectivamente 18 e 15 g/vaso. Como pode-se observar, os valores encontrados para a MS, estão bem próximos, o que nos sugere que sob efeito da maior concentração de $\mathrm{N}$, foi superior a capacidade da planta em absorvê-lo e metabolizá-lo, caracterizando uma adubação de luxo.

Em termos de produtividade, a maior média para a variável analisada $25 \mathrm{~g}$ de matéria seca/ vaso, foi obtida com a dosagem de $120 \mathrm{~kg} \mathrm{~N} / \mathrm{ha}^{-1}$ e não foram observados incrementos na variável me estudo, a medida em que a dosagem de $\mathrm{N}$ foi aumentada no meio de cultivo (Figura 2).

Figura 2: Massa Seca de arroz ( Oryza sativa L), submetidas a doses crescentes de nitrogênio. Fonte: Própria

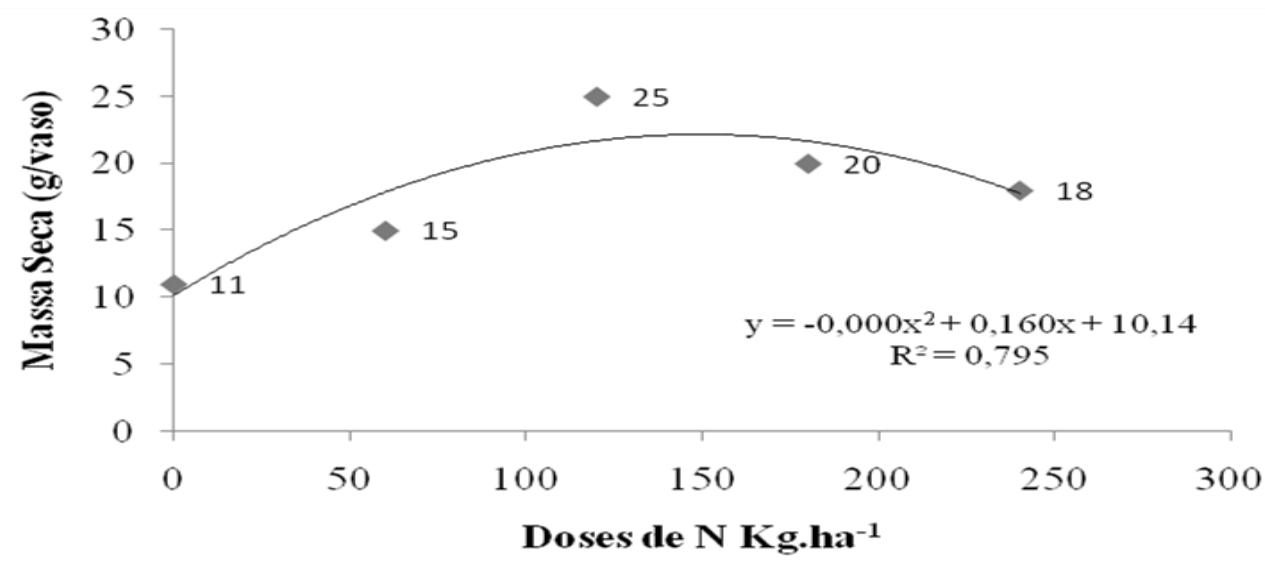


Menegatti et al., (2002), em experimento com gramíneas do gênero Cynodon, comprovaram a eficiência na utilização de nitrogênio usando três variedades; capim Tifton 85 Coastcross e Tifton 68. O capim Tifton 85 apresentou os maiores valores, 10,70 kg de MS por kg de nitrogênio aplicado, na dose de $100 \mathrm{~kg} \mathrm{de} \mathrm{N/} \mathrm{ha-1.}$

À medida que se elevaram as doses de nitrogênio, ocorreu uma redução da eficiência de utilização deste nutriente pelas gramíneas. Scivittaro \& Machado (2004), em um experimento indicaram que em termos de produtividade de plantas de arroz, as doses ótimas de nitrogênio para o crescimento da cultura são de 80 e $120 \mathrm{~kg} \mathrm{~N} / \mathrm{ha}^{-1}$.

As médias do número produtividade de grãos, em função de doses de $\mathrm{N}$, testadas, ajustaram-se a modelos de regressão quadrática $\mathrm{R}^{2}$ de $82 \%$, demonstrando boa precisão (Figura 3). A máxima produtividade $100 \mathrm{Kg} \mathrm{ha}^{-1}$ foi obtida com a dosagem intermediária de nitrogênio $180 \mathrm{Kg} \mathrm{ha}^{-1}$, sendo observados decréscimos significativos na variável analisada a medida em que as dosagens do nutriente foram aumentadas no meio de cultivo.

Figura 3: Produtividade de grãos de plantas de arroz (Oryza sativa L), submetidas a doses crescentes de nitrogênio. Fonte: Própria

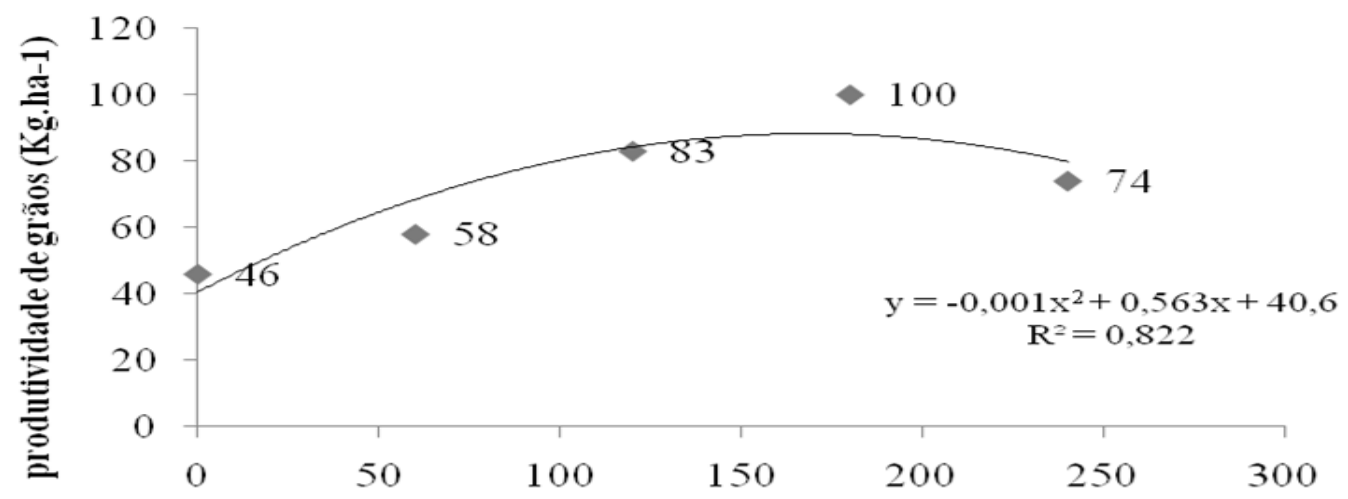

Doses de N Kg.ha-1

Estes resultados corroboram a afirmação de Oliveira et al. (2011), que verificaram efeitos significativos e quadráticos da aplicação de N, para produtividade em plantas de arroz. Pesquisas realizadas por Medeiros et al. (2007), mostram que plantas de arroz apresentaram maior produtividade e incremento nas características agronômicas quando utilizada a dosagem de $141 \mathrm{~kg} \mathrm{ha}^{-1} \mathrm{~N}$, o que consubstancia os resultados encontrados neste trabalho, cujos valores de produtividade máxima foram obtidos com nitrogênio à $180 \mathrm{Kg} \mathrm{ha}^{-1}$.

Para o conteúdo de pigmentos cloroplastídicos (Figura 4), os tratamentos com baixa e alta suplementação nitrogenada $60 \mathrm{Kg} \mathrm{ha}^{-1}$ e $240 \mathrm{Kg} \mathrm{ha}^{-1}$, induziram aos menores valores de clorofila $b$ e total (Figuras 4; b e c), em relação às plantas que receberam suplementação nitrogenada de $120 \mathrm{ha}^{-1}$ e $180 \mathrm{ha}^{-1}$. Sob tratamento com $180 \mathrm{Kg} \mathrm{ha}^{-1}$, houve incrementos significativos $(\mathrm{p}>0,01)$ nos teores de clorofilas $a, b$ total e carotenóides o que promoveu valores 
máximos para as variáveis analisadas, respectivamente de 22, 15, 37 e $12 \mathrm{mg} \cdot \mathrm{g}^{-1}$.

Figura 4: teor de Clorofila $a$ (a); clorofila $b$ (b); clorofila total (c) e carotenóides (d) em plantas de arroz ( Oryza sativa L), submetidas a doses crescentes de nitrogênio. Fonte: Própria
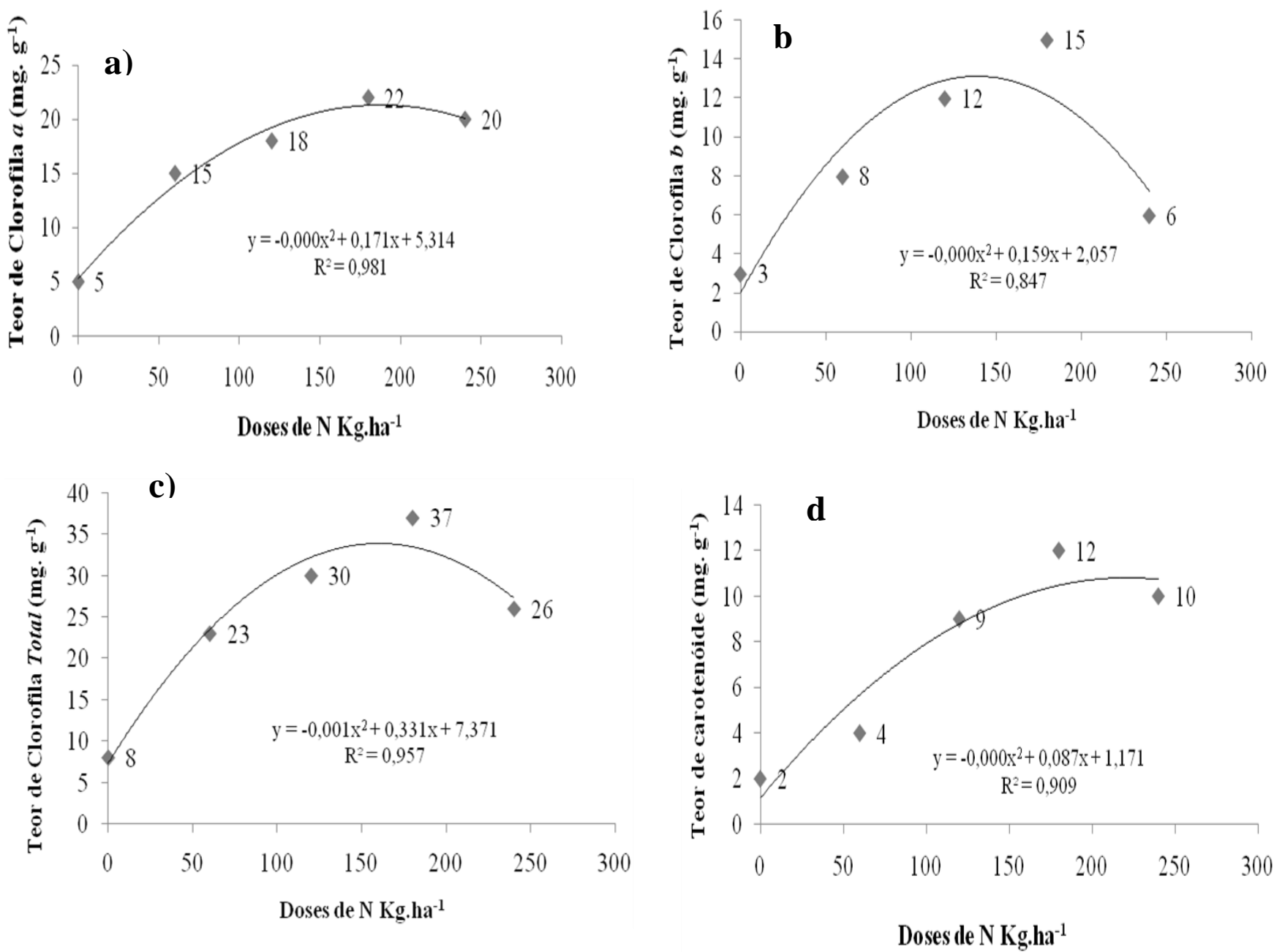

Neste estudo, foi possível diagnosticar diferenças no estado nutricional das plantas em função da dose de N. Atualmente, tem sido proposta a análise do teor de verde das folhas para avaliar o estado de nitrogênio da planta, devido à alta correlação que existe entre a intensidade do verde e o teor de clorofila com a concentração de N na folha (MARENCO \& LOPES, 2007). Essa relação é atribuída, principalmente, ao fato de que 50 a $70 \%$ do $\mathrm{N}$ total das folhas ser integrante de enzimas que estão associadas aos cloroplastos (WOOD et al.,1993; CHAPMAN \& BARRETO, 1997).

O aumento do teor de clorofilas (Figura 4) nas plantas de arroz, é consequência do aumento do metabolismo do nitrogênio. O nutriente faz parte da composição química da clorofila, o que o torna elemento fundamental no processo (MARENCO \& LOPES, 2007). Sob 
efeito da dosagem máxima de $\mathrm{Kg} \mathrm{ha}^{-1} \mathrm{~N}$, houve redução de $60 \%$ nos teores de clorofila $b$ (Figura 4,b), em relação àqueles observados para o tratamento com $180 \mathrm{Kg} \mathrm{ha}^{-1}$.

Para ser assimilado pelas plantas, o $\mathrm{NO}_{3}{ }^{-}$precisa ser reduzido a $\mathrm{NH}_{3}$. A enzima nitrato redutase (NR) catalisa a redução do nitrato para nitrito e, na sequência, a nitrito redutase (NiR) promove a redução do nitrito gerando $\mathrm{NH}_{3}$ (LEA et al. 1990). A incorporação do $\mathrm{NH}_{3} \mathrm{em}$ moléculas orgânicas, seja ela gerada pela redução de $\mathrm{NO}_{3}{ }^{-}$ou por outros processos metabólicos (p. ex.: absorção de $\mathrm{NH}_{4}{ }^{+}$do solo, fotorrespiração, catabolismo de aminoácidos), é catalisada pela glutamina sintetase, numa reação dependente de ATP (ABD- ELBAKI et al., 2000; MILLER et al., 2007).

Segundo Dwyer et al., (1995), quando absorvido em excesso, acumula-se como nitrato e, desse modo, supera a capacidade metabólica das plantas em assimilá-lo e catalizá-lo em enzimas e proteínas envolvidas nas etapas de crescimento e de desenvolvimento vegetal. Nessa forma de $\mathrm{NO}_{3}{ }^{-}$, o $\mathrm{N}$ não se associa à molécula de clorofila, o que em partes pode justificar o decréscimo observado na concentração do pigmento fotossintético, na medida em que as doses de nitrogênio foram aumentadas no meio de cultivo (Figura 4; a e b).

Além disso, a partir dos resultados encontrados nesta pesquisa, considera-se que os decréscimos nos teores de clorofilas representam um indicativo da diminuição da capacidade fotossintética das plantas, o que, provavelmente, está relacionado à diminuição no teor da ribulose-1,5-bisfosfato carboxilase/oxigenase (Rubisco), a proteína mais amplamente distribuída no reino vegetal, nas folhas, e não à sua atividade específica (atividade por unidade de proteína solúvel), o que justifica desse modo a menor produtividade da cultura.

Todo o processo fotossintético inicia-se com a absorção e transferência de energia pelos pigmentos fotossintéticos encontrados nos complexos-antena dos fotossistemas. As clorofilas e os carotenoides são, então, responsáveis pela transformação da luz solar em energia química. O impacto negativo da suplementação máxima de nitrogênio $240 \mathrm{Kg} \mathrm{ha}^{-1}$ utilizada neste estudo, sobre o conteúdo de pigmentos cloroplastídicos, influenciou diretamente na menor produtividade das plantas de arroz. Segundo Makino (2011) o potencial fotossintético das plantas pode ser fator importante para determinar o potencial de produção de biomassa da cultura.

\section{CONCLUSÕES}

A dosagem de $180 \mathrm{~kg} \mathrm{~N} / \mathrm{ha}^{-1}$, promoveu os maiores incrementos nas variáveis de crescimento, acúmulo de matéria seca, produtividade de grãos e teor de pigmentos cloroplastídicos na cultivar BRS Jaçanã. Exceto para a variável clorofila $b$ em que os maiores 
incrementos foram obtidos quando utilizada a dosagem intermediária de nitrogênio $120 \mathrm{~kg}$ $\mathrm{N} / \mathrm{ha}^{-1}$.

Aumentos acima de $180 \mathrm{~kg} \mathrm{~N} / \mathrm{ha}^{-1}$, promoveram decréscimos em todas as variáveis analisadas, indicando que acima dessa concentração ocorreu adubação de luxo.

A suplementação com a maior concentração de nitrogênio utilizada nessa pesquisa, 240 $\mathrm{kg} \mathrm{N} / \mathrm{ha}^{-1}$, provavelmente foi acumulada no tecido vegetal, o que indisponibilizou o nitrogênio para o metabolismo das plantas, induzindo a menor síntese de proteínas e moléculas orgânicas como as clorofilas.

O nitrogênio aparece como constituinte estrutural da molécula de clorofila e o menor teor desse pigmento sob efeito da máxima suplementação nitrogenada, utilizada neste estudo, provavelmente, determinou os decréscimos nas taxas fotossintéticas com reflexos sobre a redução nos parâmetros produtivos da cultivar de arroz BRS Jaçanã.

\section{REFERÊNCIAS}

ABD-EL BAKI, G.K.; SIEFRITZ, F.; MAN, H.M.; WEINER, H.; KALDENHOFF, R.; KAISER, W. M. Nitrate reductase in Zea mays L. under salinity. Plant, Cell and Environment, v. 23, p. 515-521, 2000.

ARF, O.; RODRIGUES, R.A.F.; CRUSCIOL, C.A.C.; SÁ, M.E.; BUZETTI, S. Manejo do Solo e Adubação Nitrogenada para Cultivares de Arroz de terras altas irrigadas por aspersão. Scientia Agrícola, Piracicaba, v.60, n.2, p.348-352, 2003.

ARGENTA, G. et al. Adubação nitrogenada em milho pelo monitoramento do nível de nitrogênio na planta por meio do clorofilômetro. Revista Brasileira de Ciência do Solo, v.27, p.109-119, 2003.

ARNON, D. I. Copper enzymes in isolated chloroplasts: polyphenoloxydase in Beta vulgaris. Plant Physiology, Maryland, v. 24, n. 1, p. 1-15, 1949.

CHAPMAN, S. C.; BARRETO, H. J. 1997. Using a chlorophyll meter to estimate specific leaf nitrogen of tropical maize during vegetative growth. Agronomy Journal, v. 89, p. 557-562.

COMISSÃO DE QUÍMICA E FERTILIDADE DO SOLO - RS/ SC. Recomendações de adubação e calagem para os estados do Rio Grande do Sul e de Santa Catarina. Passo Fundo: SBCS - Núcleo Regional Sul, 2004.

COSTA, N. R.; ANDREOTTI, M.; LOPES, K. S. M.; YOKOBATAKE, K. L. A.; LIMA, C. G. R. Winter bean productivity under Urochloa straw fertilized with nitrogen. Revista Caatinga, Mossoró, v. 29, n. 1, p.133-142, 2016.

DWYER, L.M.; ANDERSON, A.M.; MA, B.L.; STEWART, D.W.; TOLLENAAR, M. e GREGORICH, E. Quantifying the nonlinearity in chlorophyll meter response to corn leaf nitrogen concentration. Canadian Journal of Plant Science, v.75; p.179-182, 1995. 
FERREIRA, D.F. Sisvar: a computer statistical analysis system. Ciência e Agrotecnologia, Lavras, v. 35, n. 6, p. 1039-1042, 2011.

FREITAS, J.G. et al. Resposta de cultivares de arroz irrigado ao nitrogênio. Sci. Agric., Piracicaba, v.58, n.3, p.573-579, 2000.

GOMES, A.S.; MAGAlHÃES, A.M. Arroz Irrigado no Sul do Brasil. Brasília:Embrapa, 2004.

He WM, YU GL, SUN ZK. 2011. Nitrogen deposition enhances Bromus tectorum invasion: biogeographic differences in growth and competitive ability between China and North America. Ecography v.34; p.1059-1066.

MAKINO, A. Photosynthesis, grain yield, and nitrogen utilization in rice and wheat. Plant Physiology, Waterbury, v.155, p.125-129, 2011.

MARENCO, R. A.; LOPES, N. F. 2007. Fisiologia vegetal: fotossíntese, respiração, relações hídricas e nutrição mineral. 2 ed. Viçosa: Editora UFV, 469 p.

MEDEIROS, R. D. de et al. Rendimento de cultivares de arroz irrigado BRS Jaburu e IRGA 417 sob níveis de nitrogênio aplicados em cobertura em várzea de Roraima. In: CONGRESSO BRASILEIRO DE ARROZ IRRIGADO, 6.; REUNIÃO DA CULTURA DO ARROZ IRRIGADO, 27., 2007, Porto Alegre. Anais... Porto Alegre: Orium, 2007b. p. 619-620.

MOLLER, I.M.; JENSEN, P.E.; HANSSON, A. Oxidative modifications to cellular components in plants. Annual Reviews Plant Biology.,58:459-481, 2007.

OLIVEIRA FABRE, D. V., CENTENO CORDEIRO, A. C., BARBOSA FERREIRA, G., ALCÂNTARA VILARINHO, A., \& DANTAS DE MEDEIROS, R. (2011). Doses e épocas de aplicação de nitrogênio em arroz de várzea. Pesquisa Agropecuária Tropical, v.41, p.1.

NASCENTE, A.S.; KLUTHCOUSKI, J.; RABELO, R.R; OLIVEIRA, P.; COBUCCI, T.; CRUSCIOL, C.A.C. Produtividade do arroz de terras altas em função do manejo do solo e da época de aplicação de nitrogênio. Pesquisa Agropecuária Tropical, Goiânia, v.41, n.1, p. 6065, 2011.

PIEKIELEK, W.P. e FOX, R.H. Use of a chlorophyll meter to predict sidedress nitrogen requirements for maize. Agronomy Journal, v.84; p.59-65, 1992.

SCIVITTARO, W.B.; MACHADO, M.O. Adubação e calagem para a cultura do arroz irrigado. In: GOMES, A.S.; MAGALHÃES JÚNIOR, A.M. de. Ed. Arroz irrigado no Sul do Brasil. Brasília; Embrapa Informação Tecnológica, 2004. p. 259- 303.

WOOD, C. W.; REEVES, D. W.; HIMELRICK, D. J. 1993. Relationships between chlorophyll meter readings and leaf chlorophyll concentration, $\mathrm{N}$ status, and crop yield: a review. Proceedings Agronomy Society of New Zealand, v. 23, p. 1-9. 